\title{
Ascription of the differences between Germany and Uganda's Land Use, Land-Use Change, and Forestry sector greenhouse gas methodologies for inventory improvement
}

\author{
Michael Mugarura ${ }^{1,2}\left(\right.$ Dolfgang Stümer ${ }^{1} \cdot$ Karsten Dunger $^{1} \cdot$ Andreas Bolte $^{1}$. \\ Matt Ramlow ${ }^{3} \cdot$ Emmanuel Ackom $^{4}$. Steffi Röhling ${ }^{1}$
}

Received: 15 July 2020 / Accepted: 7 May 2021 / Published online: 29 June 2021

(C) The Author(s) 2021

\begin{abstract}
Germany, as an Annex I Party is expected to prepare and submit annual Greenhouse Gas (GHG) Inventories of emissions and removals, including Land Use, Land-Use Change, and Forestry (LULUCF) sector. Uganda, a non-Annex 1 party, is institutionalizing a sustainable national GHG inventory system. The LULUCF sector is a key emission source and plays a vital role in these two countries' GHG inventories. This research analyzes the differences between applied LULUCF methodologies in Uganda as a developing country and Germany as a developed country with a particular focus on the forestry sector. It further analyzes the root cause factors for the different approaches, existing gaps and gives recommendations for future inventory improvement. The intricate institutional, policy framework, expertise, and applied methodological approaches for carbon change estimations in biomass pools are analyzed. Uncertainty analysis and time-series consistency process is reviewed with regard to how the countries' quality assurance/control (QA/QC) and verification approaches adhere to the transparency framework. Resource limitations and data collection challenges dictate that Uganda uses the tier 1 methodological approach for emissions inventory. Consolidation and institutionalization of the GHG process will improve inventory accuracy while enhancing adherence to climate commitments. Germany uses higher tiers. Besides, government support for planned improvements using the recently developed countryspecific biomass functions for estimating belowground biomass of silver birch, oak, and Scotch pine tree species will be essential for improving inventory quality. Operationalization of the inventory plan (IP) will be critical in driving inventory improvements geared towards time-series consistency, comparability, and transparency.
\end{abstract}

Keywords Biomass stock - Emission factor - Uncertainty analysis - Allometric equations · National Forest Inventory $\cdot$ Stock-difference method

Michael Mugarura

mugarura.michael@gmail.com

Extended author information available on the last page of the article 


\section{Introduction}

There is a clear distinction of obligations between Annex 1 and non-Annex 1 countries such as Germany and Uganda, respectively, under the Kyoto Protocol of the United Nations Framework Convention on Climate Change (UNFCCC) (Kartha and Erickson 2011). These differences have increasingly become less delineated especially in light of the 2015 Paris Agreement (PA) (Lahn and Sundqvist 2017; Mbeva and Pauw 2016). Unlike the UNFCCC, the PA does not refer to Annex 1, non-Annex 1 (Den Elzen and Höhne 2008), or any specific country groups; it highlights them as developed and developing countries (Obergassel et al. 2015). This differentiation of developed and developing countries is still a critical challenge in the operationalization of the PA (Ari and Sari 2017). Germany, as an Annex I Party to the UNFCCC and its Kyoto Protocol (KP) (Wang and Wiser 2003), is expected to prepare and submit annual national Greenhouse Gas Inventories (GHGI) of emissions and removals. The GHGI must include emissions from the Land Use, Land-Use Change, and Forestry (LULUCF) sector (Höhne et al. 2007). Uganda is a non-Annex 1 party, classified as a developing country under the PA (Pauw et al. 2019; Voigt and Ferreira 2016), and a sub-Saharan region member. Similar to many developing countries, Uganda is grappling with the challenge of developing and institutionalizing a sustainable national GHGI system (Henry et al. 2011). LULUCF, particularly the forest sector, is one of the key categories within Uganda's GHGI (Mugagga et al. 2017; Namanya 2008). Findings show that the absence of a dynamic and functional GHGI management system has greatly hindered effective reporting to the UNFCCC, KP, and currently to the PA (Ari and Sari 2017). The separate reporting processes between developed and developing countries have introduced the inherent systematic segregation of parties thus limiting their interactions and sharing of expertise/skills. This interaction could help developing countries to improve on their inventories and developed countries to share good practices with the former. Uganda, like other developing countries, is grappling with challenges from this oversight. A situation well epitomized by the slow operationalization progress of the country's GHGI, hence the importance of this research.

This research analyzes differences between the national GHGI processes and specifically, the applied LULUCF methodologies in Uganda as a developing country, and Germany as a developed country with emphasis on the forest sector. It highlights the driving factors for the different methodological approaches between the two countries, and how they can improve in areas of inventory similitude. There are existing inventory gaps the research shows that can be addressed through cross-pollination of ideas from the two countries. This article sequentially investigates institutional arrangements, policy and legal frameworks, data collection methods, carbon stocks, emission factors, allometric equations, uncertainty analysis, and emission pools for the two countries. Existing methodological gaps are identified in the national GHGI employed in each country. Finally (but not the least), the study provides recommendations for possible consideration to make improvements in the studied area.

\subsection{Historical evolution of emissions inventory and reporting system(s)}

\subsubsection{Historical context}

A review of Germany's historical emissions from the (1800s) shows distinct relationships on pollution and emissions trends (Cohen et al. 2018; Hake et al. 2015). The 
prevailing circumstances like wars, industrial revolution, and economic fluctuations had significant impacts on the generated historical emissions. The two world wars (1914-1918 and 1939-1945 respectively) had a significant impact on Germany's emission trends as decreases were recorded (Granier et al. 2011). The rest of the period showed consistent increase in the recorded emission trends. These trends peaked in 1979 at 1390 million tonnes $\mathrm{CO}_{2}$ equivalents (Kerstine et al. 2020). During the 1980s, West Germany became one of Europe's pacesetters in the development and introduction of air pollution control policies (Weidner and Mez 2008). Germany started to systematically get involved in international and European negotiations like the long-range transboundary air pollution (Sprinz and Wahl 1998; Zito 2000). Uganda got independence from the UK in 1962 (Mutibwa 1992). However, the country struggled with the establishment of legal and institutional frameworks due to the dynamic political landscape that ensued. It would take two decades later in 1984, for Uganda to start establishing policy and institutional frameworks for proper governance. A few more years elapsed and in 1990, the country started participating in climate change dialogues. Uganda signed the UNFCCC in 1992 and ratified the KP in 2002 (MWE 2019). Since that time, the government has been able to come up with a number of adaptation and mitigation measures. These have mainly been supported by external sources and to a limited extent from the country's domestic resources (Tumushabe et al. 2013).

\subsubsection{Current context}

Germany started emissions reporting in the early 1980s through the Germany Environment Agency (UBA) (Jänicke 2010; Weidner and Mez 2008), by collecting and calculating air pollutants. Germany calculated and established through UBA its emissions base value of 1.25 million tonnes of carbon dioxide equivalents in 1990 (Nick and Ulf 2018). This is the national benchmark for measuring progress on the set National GHG targets. A cabinet decision in 1990 set a 2005 National target of reducing the country's emission by 25\% below the 1990 levels (Weidner and Mez 2008). The first National Communication (NC) and the second NC followed shortly afterwards in 1994 and 1997 respectfully. The country wants to attain carbon neutrality by the year 2050 (Meeus et al. 2012). Another target is to cut emissions by at least $55 \%$ by 2030 compared to 1990 levels. The annual reduction targets for the main sector players up to 2030 are clearly stated in Germany's 2019 climate law. Uganda's National Climate Change Policy (NCCP) 2015 provides the policy framework for domestic climate change action. The country is yet to establish a legal framework on climate change (Ampaire et al. 2017). This is a big challenge as climate change actions cannot be enforced without legal backing. The current proposed climate change bill is yet to be tabled for public debate. The proposed act is a framework in nature. Therefore, the different line ministries will be responsible for developing their own climate change measures. The minister(s) will have the power to make rules and regulations providing for specific adaptation and mitigation activities when required. The law will enable Uganda to pursue voluntary mitigation targets under the PA aimed at reducing greenhouse gas emissions. Uganda's National Determined Contribution (NDC) sets a $22 \%$ emissions reduction target by 2030 compared to Business-as-Usual Scenario (MWE 2015).

\subsection{Institutional arrangements}

The institutionalization of Germany's National Inventory System is on three levels. The first level, being a ministerial-level, is located within the federal government (Bulkeley and Kern 
2006). The second and third levels are under the oversight of the UBA (Beck et al. 2009; Weidner and Mez 2008) and the responsible sector respectively. The UBA has a Central System on Emissions (CSE) database which acts as the national database for emissions calculation and reporting (Schlenzig 2002). It works as a central storage of all information required for emissions calculation (methods, activity data, and emission factors). The Thünen Institute (TI) for Forest Ecosystems is responsible for the forestry inventory within the LULUCF sector working group (Wellbrock and Bolte 2019). In addition to other tools, the TI created an online interactive platform called LULUCF WIKI, which allows storage, dynamic interaction, and updating of forestry inventory data and metadata. It is used as an online central platform that has enhanced the simultaneous and remote improvement of draft documents by different officers stationed in different sites. This aspect has led to improved coordination and versioning of uploaded documents. It also serves as the central documentation that supports the inventory review process and allows for a clean inventory check. A working group on emissions inventories and a quality system of emissions (QSE) were established within UBA for coordination and implementation of pertinent work respectively. The Federal Ministry for the Environment Nature Conservation and Nuclear Safety (BMU) is responsible for the emissions calculations. The Federal Statistical Office is also an active player in GHGI as it is the central office for all statical data and information for the country (Braun et al. 2018). In many areas, calculations for different sectors are based on highly differentiated activity data obtained via national data sources. Germany's 2020 National Inventory Report (NIR) shows that activity data are combined, depending on the emission sources involved. This is done, either with national emission factors or with the standard emission factors of the 2006 IPCC Guidelines. Changes in biomass carbon stocks are estimated on the basis of harvest statistics. National Forest Inventory (NFI) and pertinent scientific literature are also used in conjunction with area data. The Ministry of Water and Environment (MWE) is the principal institution for all activities related to climate change in Uganda (Ampaire et al. 2017). Uganda has an established Climate Change Department (CCD) within MWE, responsible for the preparation of all national and international communications. CCD is also responsible for the management of all climate change-related actions in the country, and thus plays host to Uganda's national GHGI system. The system incorporates the institutional, legal, and procedural arrangements for estimating, reporting, and archiving GHG emissions and sinks. It also covers all sectors of anthropogenic activities stipulated within the Intergovernmental Panel on Climate Change (IPCC) 2006 guidelines, including the forest sector.

\subsection{National datasets}

Germany's National Forest Inventories (NFI) (Dietrich et al. 2019; Kandler 2009) and National Forest Soil Inventories (NFSI) (Wellbrock et al. 2017) are the primary source of information used for estimating forest and soil carbon stocks (Grüneberg et al. 2014; Röhling et al. 2016). The TI is responsible for collecting and analyzing NFI and NFSI data at the federal government level. In Uganda, data comes mostly from government institutions and local and international literature and to a lesser extent from individual industrial plants and professional associations (Lwasa 2017). Uganda is one of the few African nations with a long-term program aimed at accurate assessment of biomass resources and their dynamics (Avitabile et al. 2011). Data for Uganda's NFI is collected by Uganda's National Forest Authority (NFA) through National Biomass Studies (NBS), Exploratory Inventories (EI), and Permanent Sample Plots (PSP). Data on natural forests and plantations was used to develop carbon stock factors for different forest types (FREL 2018). 


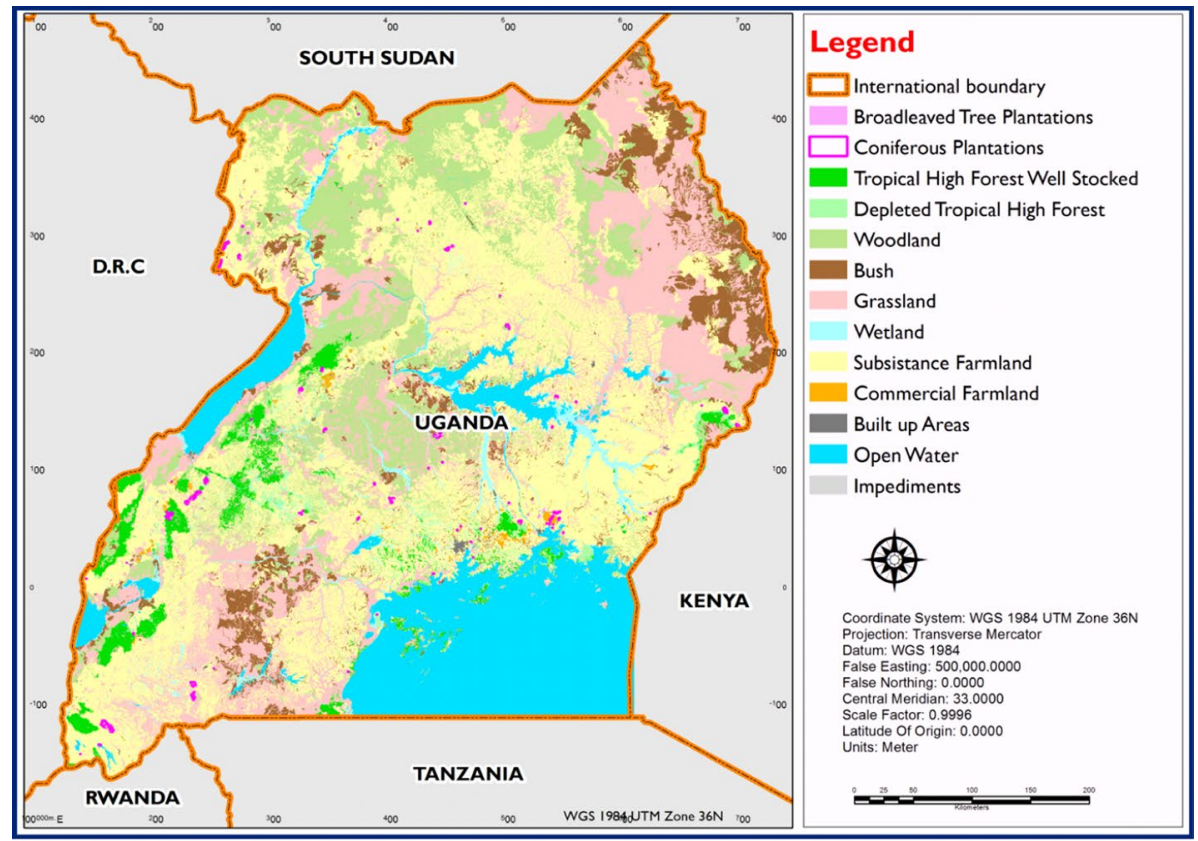

Land use/cover for Uganda for the year 1990.

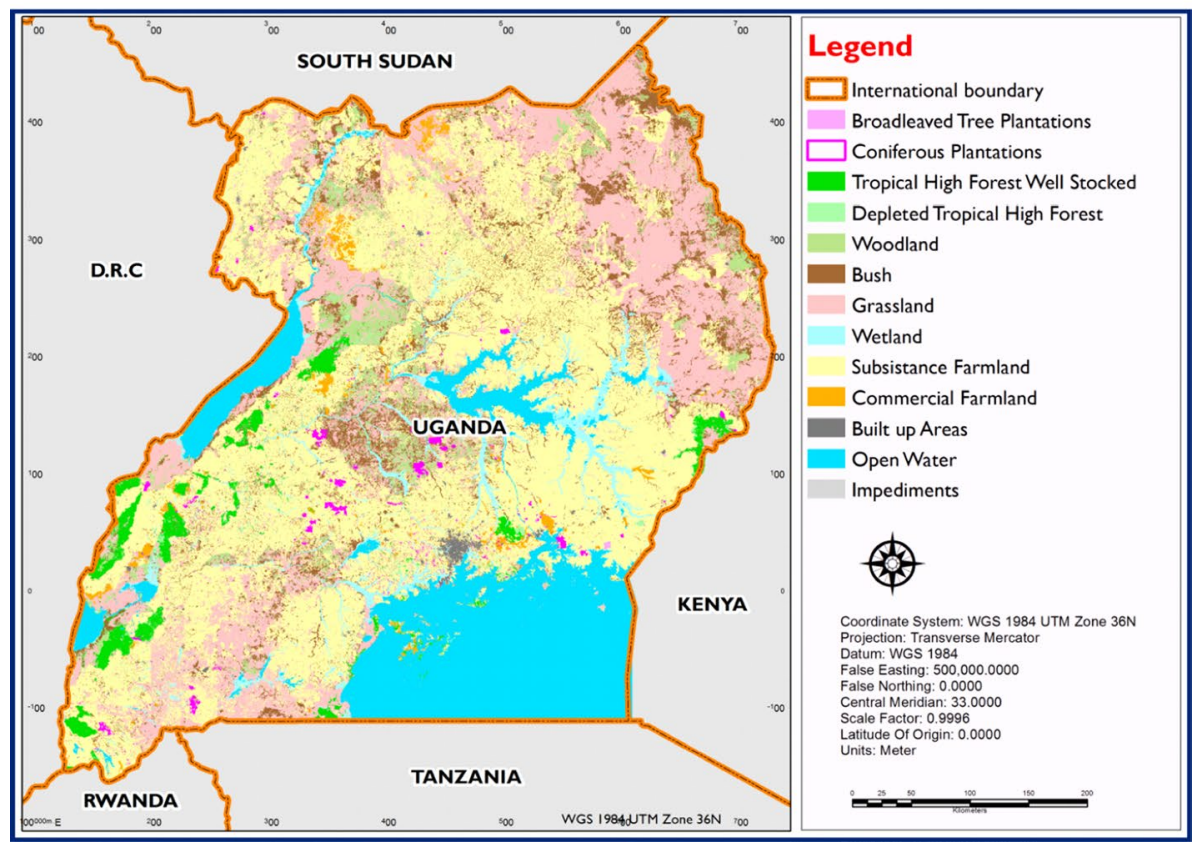

Land use/cover for Uganda for the year 2015.

Fig. 1 Land use/cover for Uganda for the year 1990 (a) and 2015 (b) respectively; source (Mwanjalolo et al. 2018) 


\subsection{Tiers}

The tier approach is given in the 2006 IPCC Guidance for National GHG Inventories (Eggleston 2008) Volume 1, Chapter 1. A tier represents a level of methodological complexity. Tier 1 is the basic method, tier 2 intermediate, and tier 3 the most demanding in terms of complexity and data requirements. Tiers 2 and 3 are sometimes referred to as higher tier methods and are generally considered to be more accurate. Germany mainly uses the tier 2 approach (Change 2006; Eggleston 2008), with country-specific data and the methods from the guidelines. The country has also been able to come up with country-specific emission factors (EF) and specific methodologies, thus employing tier 3 in its inventory. Uganda uses tier 1 with aspects of tier 2 incorporated in the forest sector due to developed country-specific allometric equations for defined tree categories (FREL 2018). Germany mainly uses country-specific EFs for the different source categories, while Uganda mainly uses IPCC default values.

\subsection{Scope}

There are clear variations in the countries' scope in terms of source categories covered, gases, and pools. In terms of source categories, both countries report on similar activities albeit under different tiers and complexities. In terms of gases, Germany reports on carbon dioxide $\left(\mathrm{CO}_{2}\right)$, nitrous oxide $\left(\mathrm{N}_{2} \mathrm{O}\right)$, and methane $\left(\mathrm{CH}_{4}\right)$ for the LULUCF sector (Polley et al. 2014). Uganda reports on $\mathrm{CO}_{2}$ only although is contemplating to start estimating $\mathrm{CH}_{4}$ and $\mathrm{N}_{2} \mathrm{O}$ emissions from biomass burning in the inventory using Global Food and Agriculture Statistics of FAO (FAOSTAT) data. In terms of pools, Germany reports on positive (source) and negative (sink) $\mathrm{CO}_{2}$ emission removals from mineral and organic soils (Prechtel et al. 2009; Röhling et al. 2016), aboveground biomass (AGB) and belowground biomass (BGB) (Röhling et al. 2016; Tiemeyer et al. 2020a, b), litter, and deadwood (Dunger et al. 2012). Germany reports also on other sources of $\mathrm{N}_{2} \mathrm{O}$ in its LULUCF inventory, including $\mathrm{N}_{2} \mathrm{O}$ and $\mathrm{CH}_{4}$ emissions from wildfires. Uganda mainly reports on AGB and BGB.

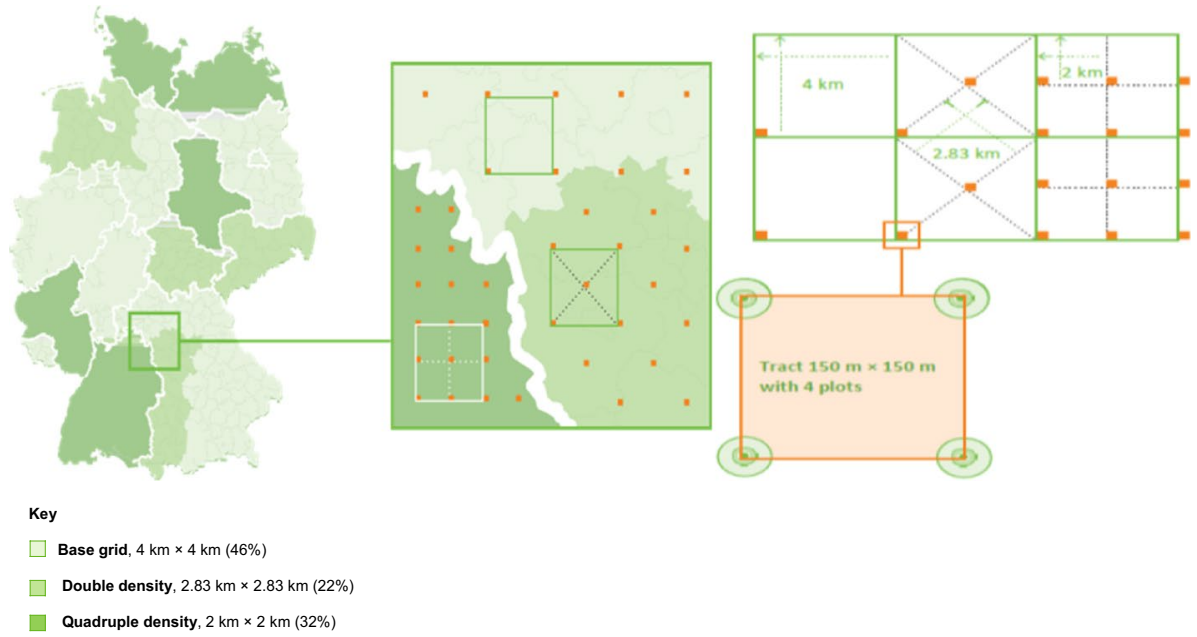

Fig. 2 Germany National Forest grid 2012; source (Polley et al. 2014) 
Table 1 Number of sampled plots which equal to the corners of clusters (the sampling unit)

\begin{tabular}{llllllll}
\hline Grid ID & Sample grid & 1987 & 2002 & 2008 & 2012 & $2017^{*}$ & $2017^{* *}$ \\
\hline 64 & $8 \times 8 \mathrm{~km}$ & N/A & 22,360 & 22,360 & 22,360 & 22,360 & 22,360 \\
16 & $4 \times 4 \mathrm{~km}$ & 62,186 & 89,641 & & 89,641 & 89,641 & \\
8 & $2.83 \times 2.83 \mathrm{~km}$ & 23,629 & 42,691 & & 48,295 & 48,295 & \\
2 & $2 \times 2 \mathrm{~km}$ & 29,481 & 47,414 & & 57,679 & 57,679 & \\
\hline
\end{tabular}

$*$ For forest/none forests decision

**Terrestrial assessments on $8 \times 8 \mathrm{~km}$ (used for ground truthing and measurements) ${ }^{1}$

\subsection{Activity data}

In Germany, the annual calculation of the total areas is carried out for subcategories land use remaining within the same land use and land-use conversion. The inventory has been carried out from 1990 to 2018 with linearly interpolation used to fill in-between gaps. In Uganda, land use land cover maps are used as a basis for activity data (Fig. 1). The year 2000 map was produced in 2015 to close the gap between the maps of 1990 and 2005 (Buyinza et al. 2014). Biomass monitoring has been done through NBS. The NBS inventory was used to assign biomass stock-values to certain land use/land cover classes, which were then mapped out to estimate their extent.

\subsection{Biomass stocks}

The German NFI is based on a systematic rectangular grid with clusters (tracts) as primary sampling units (Fig. 2) (Polley et al. 2014). The General Administrative Regulation prescribes a grid with a width of $4 \times 4 \mathrm{~km}$ as a so-called base grid. This base grid covers the complete surface of Germany with a defined starting point. The sample grid is intensified in some federal states or parts of them to a $2.83 \times 2.83 \mathrm{~km}$ or a $2 \times 2 \mathrm{~km}$ quadrangular grid (Table 1). Tracts cover forest and non-forest land throughout Germany. The tract is a quadrangle with sides of $150 \mathrm{~m}$. The sample selection on a tract corner is made according to different methods. The densities of the sampling grids in each federal state vary.

For Uganda, the country is overlaid with a grid of $5 \mathrm{~km}$ by $10 \mathrm{~km}$. At every intersection, there is a cluster of three plots, $300 \mathrm{~m}$ north, and $300 \mathrm{~m}$ south. The third plot is at $300 \mathrm{~m}$ or $600 \mathrm{~m}$ (west or east) of the intersection. Uganda's first biomass assessment was conducted in the 1990s, with the results published in 2002. The second NBS was concluded in 2009 (Fig. 3), but not officially published (NFA 2009).

Results from these studies are, however, used by the government. Other processes used for biomass assessment include EI (Fig. 3b) and use of PSP (Fig. 3c). Sampling intensity is based on population density and ecological zones. High populations have a high impact on biomass and land cover; thus, areas with high populations are given

\footnotetext{
1 For the carbon reporting, Germany uses the $8 \times 8 \mathrm{~km}$ grid only; thus, sample plots considered over the years are 22,360 .
} 


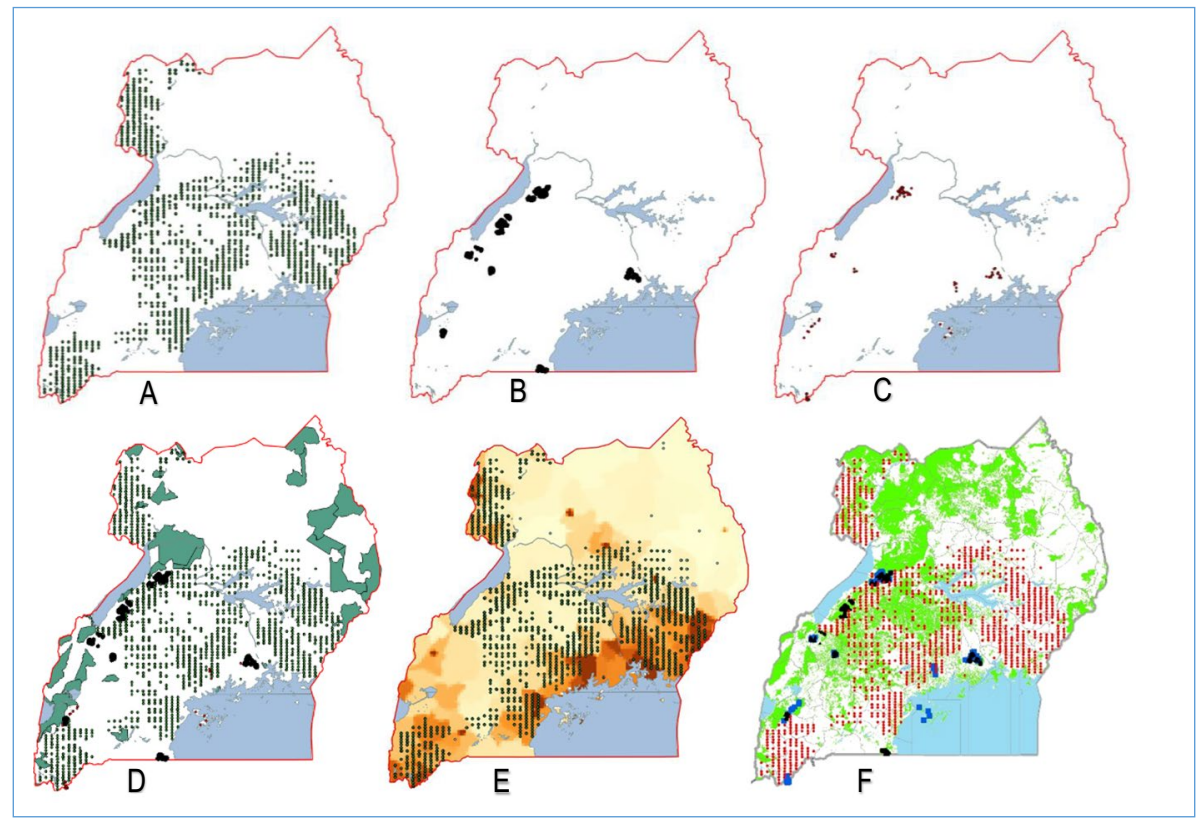

Fig. 3 Uganda's Inventory datasets; source (FRL 2017). (a) National Biomass Study (NBS). (b) Exploratory Inventory (EI). (c) Permanent Sample Plot (PSP). (d) All datasets and Uganda Wildlife Authority (UWA) protected areas. (e) NBS sample plots in Uganda on the top of population intensity map. (f) Combined NBS, EI, and PSP plots

more sampling plots than low population areas (Fig. 3e). Forest inventories in Uganda can be grouped into four broad categories as shown in Table 2.

\section{Materials and methods}

\subsection{Aboveground biomass (AGB)}

\subsubsection{Estimation of carbon change in Germany's biomass pools}

Carbon stock changes associated with changes in forest land areas are reported either under land converted to forest land and forest land converted to other land. The stock-difference method (Eq. 3) is applied at the sample plot level at time $t_{1}$ and $t_{2}$. Mean annual emissions are estimated as the ratio of the difference in stock estimates at two points in time and the number of intervening years (McRoberts et al. 2018). Germany developed her own unique sampling strategy that uses similar principles to the IPCC's stock-difference method (Röhling et al. 2016). Stock change estimations in Germany are carried out using the continuous forest inventory (Wellbrock et al., 2017) method which ultimately relates to IPCC's stockdifference method (IPCC 2006, ${ }^{2}$ Vol 4, Ch 2, Eq. 2.5). Basing on the country's national

\footnotetext{
2006 IPCC Guidelines for National Greenhouse Gas Inventories Volume 4 (Agriculture, Forestry and Other Land Use). All cited chapter references in this paper are from Volume 4 of the 2006 IPCC Guidelines.
} 


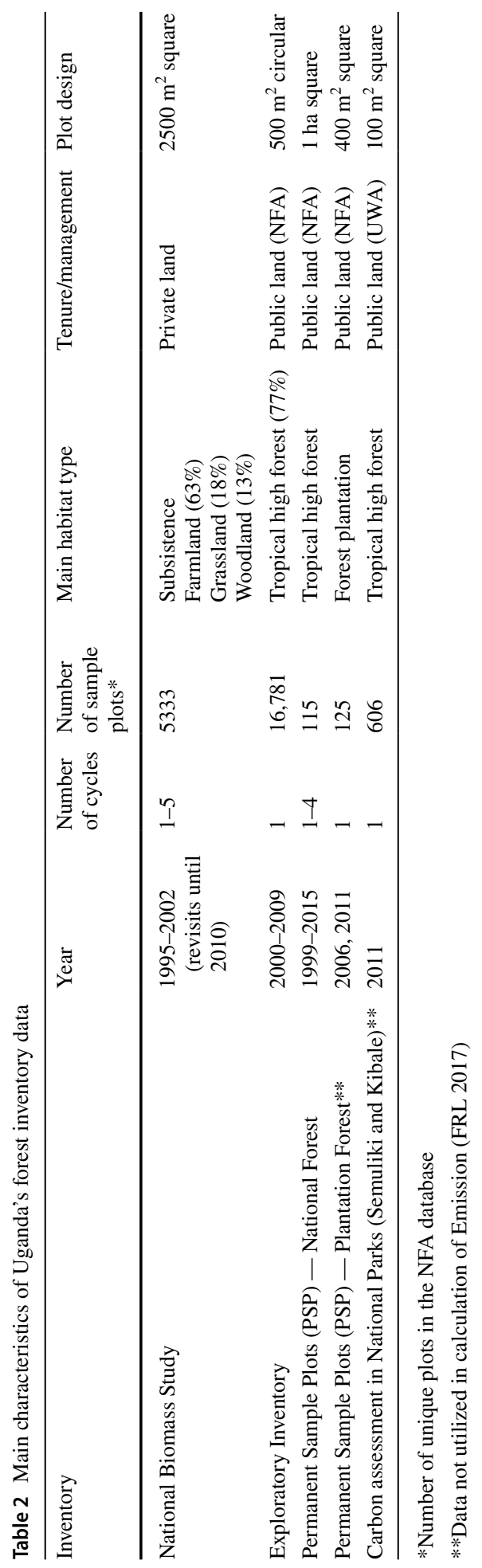


$8 \times 8 \mathrm{~km}$ sampling grid system, the NFI method was developed and used for calculation of changes between two time points. Upscaling was done only on cluster points when German NFIs were carried out (in the periods; 1987-2002, 2002-2008, and 2008-2012). The change estimate is thus based on the difference between the two estimators of the total. At the stratum level, the total change is estimated as follows:

$$
\widehat{G}_{l}=\widehat{Y}_{l}^{\left(t_{2}\right)}-\widehat{Y}_{l}^{\left(t_{1}\right)}
$$

where $G_{l}$ is the total change in stratum, $l$ is the stratum, $t$ is the time, and is the estimator of the total. The change in the area-related mean estimator is determined via:

$$
\widehat{G}_{R_{s t}}=\widehat{R}_{s t}^{\left(t_{2}\right)}-\widehat{R}_{s t}^{\left(t_{1}\right)}
$$

where $\widehat{G}_{R_{s t}}$ is the total change overall strata, is time, and $\left(\widehat{R}_{s t}\right)$ is the estimator of ratio. Consequently, annual rates of change have to be obtained via interpolation between two points in time. For the periods between inventories, 1987, 2002, 2008, 2012, and 2017, a linear interpolation was carried out. The EF for a LULUCF class is thus defined as the quotient of the area-related mean estimator and the number of years within the relevant inventory interval:

$$
E F=\frac{\widehat{G}_{R_{s t}}}{a}
$$

where $E F$ is the emission factor, $a$ the number of years, and $\widehat{G}_{R_{s t}}$ is the total change. If Eq. (3) is multiplied by the total area, it will be equivalent to the stock-difference method (IPCC 2006, Ch 2, Eq. 2.5) below;

$$
\Delta C=\frac{\left(C_{t 2}-C_{t 1}\right)}{\left(t_{2}-t_{1}\right)}
$$

where $\Delta C$ is annual carbon stock change in the pool (tonnes $\mathrm{C}$ year ${ }^{-1}$ ), $C_{t 1}$ is carbon stock in the pool at time $t_{1}$ (tonnes $\mathrm{C}$ ), and $C_{t 2}$ is carbon stock in the pool at time $t_{2}$ (tonnes C). Changes in Germany's biomass carbon stocks under forest land remaining forest land are calculated with the stock-difference method, following a tier 2 approach (IPCC 2006, Ch 2, Eq. 2.8). For land converted to forest land, changes in biomass carbon stocks are calculated following the method given by IPCC 2006, Ch 2, Eq. 2.16.

\subsubsection{Estimation of carbon stock changes in Uganda's biomass pools}

To estimate the change in carbon stocks from Land Use, Land-Use Change, and Forestry, land cover data from wall-to-wall forest mapping by NFA was used. NFA used this data to generate the six IPCC land-use categories required for land-based GHG emission calculations. Generally, Uganda uses the tier 1 gain-loss method (Eq. 5) to determine carbon changes in AGB in land remaining in the same category (IPCC 2006, Ch 2, Eq. 2.7). The tier 2 method (Eq. 6) is the general method used in category change (IPCC 2006, Ch 2, Eq. 2.15). Nevertheless, the country is currently using the IPCC 2006 Software $^{3}$ for GHGI, where forest land category is given special treatment. This is because it is the only category

3 IPCC Inventory Software. https://www.ipcc-nggip.iges.or.jp/software/index.html 
where growth is computed by the software as a product of area and growth per hectare. Therefore, the inbuilt, equation for computing the annual increase in biomass carbon of forest land remaining forest land is referenced to IPCC 2006 (Ch 2, Eq. 2.9 and 2.10, not Eq. 2.7). Changes in biomass carbon stocks resulting from land-use conversion are estimated using the software inbuilt - IPCC equation for tier 1 (MWE 2019). There are a number of general assumptions and standardized default values applied within the IPCC 2006 Software. However, many of these default values are not a good representation or do not lie within the countries' specific emission value ranges. Therefore, the use of inbuilt higher tier equations does not guarantee better quality results. A tier 1 approach is used in determining AGB, soil organic matter, deadwood, and litter due to the unavailability of countryspecific EFs and inadequate data disaggregation. The assumption that the net stock change is zero is applied.

$$
\Delta C=\Delta C_{G}-\Delta C_{L}
$$

where $\Delta C$ is the annual carbon stock change in the pool (tonnes $\mathrm{C}$ year ${ }^{-1}$ ), $\Delta C_{G}$ is the annual gain of carbon (tonnes $\mathrm{C}$ year ${ }^{-1}$ ), and $\Delta C_{L}$ is the annual loss of carbon (tonnes $\mathrm{C}$ year $^{-1}$ ). The gains were estimated as a product of area and biomass increment as per IPCC 2006 guidelines (Ch 2, Eq. 2.9)

$$
\Delta C_{B}=\Delta C_{G}+\Delta C_{\text {CONVERSION }}-\Delta C_{L}
$$

where $\Delta C_{B}$ is the annual change in on land converted to other land-use categories in tonnes $\mathrm{C}$ year $^{-1}$, annual increase in carbon stocks in biomass due to growth on land converted to another land-use category, in tonnes $\mathrm{C}$ year $^{-1} ; \Delta C_{\text {CONVERSION }}$ is the initial change in carbon stocks in biomass on land converted to other land-use category, in tonnes $\mathrm{C}$ year ${ }^{-1}$; and $\Delta C_{L}$ is annual decrease in carbon stocks due to losses from harvesting, fuelwood gathering, and disturbances on land converted to other categories, in $\mathrm{C}$ year ${ }^{-1}$.

\subsubsection{Derivation of individual-tree biomass}

The AGB in Germany is estimated employing biomass allometric equations derived from the NFI data. Germany's inventory relies heavily on a study by Kändler and Bösch (2013), which focused on the species of spruce, pine, beech, and oak (most prominent in Germany). All other tree species, except for soft hardwood species, were included in those four species groups. In Uganda, the biomass equations were developed from the NBS of 1992 and 2003. They were later adjusted by the unpublished work of Velle (1997) (in Buyinza et al. 2014) and used to compute the biomass stocks often used for carbon estimates. A comparative analysis between the model from Chave et al. (2014) and national equations developed from the NBS studies was carried out. The analysis showed that there were no significant differences in the AGB estimated by the model of Chave et al. (2014) and that of the NBS equations. Thus, the equation (Chave et al. 2014) was adopted because it was comparable to locally developed equations and, unlike the NBS equations, crown diameter measurements are not required.

\subsubsection{Conversion into AGB for individual-trees}

Germany's biomass allometric equations are based on the tree-species groups (Röhling et al. 2016) which are divided into three parts. Trees $\geq 10 \mathrm{~cm}$ diameter at breast height 
(DBH), trees $\geq 1.3 \mathrm{~m}$ height and $<10 \mathrm{~cm} \mathrm{DBH}$, and trees $<1.3 \mathrm{~m}$ height. Trees that are less than $1.3 \mathrm{~m}$ in height (and for which no DBH can be measured) cannot be reasonably differentiated by the aforementioned groups. For this reason, such trees are differentiated only in terms of whether they are coniferous or broadleaf trees. In conversion areas, the functions were smoothed with the help of statistical procedures. This prevented any overlaps between the functions that might otherwise have occurred.

Trees with at least $10 \mathrm{~cm} \mathrm{DBH}$

$$
Y_{B I O M_{0}}=b_{0} e^{b_{1}} \frac{D B H}{D B H+K_{1}} e^{b_{2}} \frac{D 03}{D 03+K_{2}} H^{b_{3}}
$$

where $Y_{B I O M_{0}}$ represents aboveground biomass in kilograms per individual tree, $b_{1,2,3}$ and $K_{1,2}$ are the coefficients of the Marklund function (Bolte et al. 2003; Drexhage and Colin 2001; Johansson and Hjelm 2012), $D B H$ is the diameter at breast height in centimeters, $D 03$ as the diameter in centimeters at $30 \%$ of the tree height, and $H$ is the tree height in meters.

Trees $>1.3 \mathrm{~m}$ height and $<10 \mathrm{~cm} \mathrm{DBH}$

$$
Y_{B I O M_{0}}=b_{0}+\left(\frac{b_{s-} b_{0}}{d_{s}^{2}}+\left(D B H-d_{s}\right)\right) D B H^{2}
$$

where $Y_{B I O M_{0}}$ represents AGB in kilograms per individual tree, $b_{0, s}$ are the coefficients of the Marklund function, $D B H$ is the diameter at breast height in centimeters, and $d_{s}$ is the diameter-validity boundary for this function which equals to $10 \mathrm{~cm}$.

Trees $<1.3$ m height

$$
Y_{B I O M_{0}}=b_{0} H_{1}^{b}
$$

where $Y_{B I O M_{0}}$ represents AGB in kilograms per individual tree, $b_{0,1}$ are the coefficients of the function, and $H$ tree height in meters. Uganda decided to use the equation from Chave et al. (2014) because it is comparable to locally developed equations;

$$
\begin{gathered}
A G B_{e s t}=0.0673 \times\left(\rho D^{2} H\right)^{0.976} \\
(\sigma=0.357, \mathrm{AIC}=3130, \mathrm{df}=4002)
\end{gathered}
$$

where $A G B_{\text {est }}$ is estimated AGB $(\mathrm{kg}), \rho$ is wood specific gravity $\left(\mathrm{g} \mathrm{cm}^{-3}\right), D$ is trunk diameter $(\mathrm{cm})$, and $H$ is total tree height $(\mathrm{m})$.

\subsection{Belowground biomass (BGB)}

The BGB for the major tree species in Germany is derived via allometric equations based on peer-reviewed articles (Bolte et al. 2003; Johansson and Hjelm 2012; Neubauer et al., 2015a, b; Wellbrock et al. 2017). This addressed the need for consistency between the method used to derive AGB and that used to derive BGB. It also addresses the need for overall clarity and transparency. The TI of Forest Ecosystems, through Röhling et al. (2019), has of recent developed separate country-specific biomass functions for derivation of BGB for birch, oak, and pine. As an alternative to fitting a linear model to logtransformed measurements, Röhling et al. (2019) used the weighted nonlinear least-squares regression. It was implemented by the "stats" package of the R software by fitting a power function to the data. Estimates for the coefficients $\beta 1$ and $\beta$ were obtained. 
Table 3 Estimated coefficients for dry mass estimations of birch, oak, and pine roots (Röhling et al. 2019)

\begin{tabular}{llllll}
\hline Tree species & Coefficient & Coefficient estimates & CI & ME & RMSE \\
\hline Birch & $\beta 1$ & 0.04582 & $0.0092-0.0824$ & 0.81 & 26.9 \\
& $\beta 2$ & 2.23951 & $2.0047-2.4742$ & & \\
Oak & $\beta 1$ & 0.040113 & $0.0253-0.0548$ & 0.98 & 5.2 \\
& $\beta 2$ & 2.227842 & $2.1179-2.3377$ & & \\
Pine & $\beta 1$ & 0.010617 & $0.0053-0.0159$ & 0.95 & 13.7 \\
& $\beta 2$ & 2.593122 & $2.4549-2.7312$ & & \\
\hline
\end{tabular}

$$
B G B=\beta_{1} \cdot D B H^{\beta 2}
$$

where $B G B$ is the belowground biomass of the Individual tree, $D B H$ is the diameter at breast height, and $\beta_{1}$ and $\beta_{2}$ are the scaling coefficients (Table 3 ).

In Uganda, the considered belowground living biomass is in the form of roots. Estimation is based on roots that are $2 \mathrm{~mm}$ in size and above. Root biomass is estimated using standard relationships with AGB through the default values provided by the IPCC 2006 guidelines. BGB is calculated by applying the IPCC 2006 root-shoot conversion factors for the different forest types to the AGB from NFI data. The default value of 0.24 for tropical moist deciduous forest $\left(\mathrm{AGB}>125\right.$ tonnes $^{-1}$ ) is currently used for all categories.

\subsubsection{Conversion of individual-tree biomass to carbon}

A value of 0.5 has been applied for the conversion of biomass to carbon stocks for both countries. The differences between compartments within a given tree species are larger than the differences between tree species. The relative standard error for carbon content in wood is given by Burschel et al. (1993) as 1 to 2\%, and Weiss et al. (2000) as 2\%. Overall, therefore, $0.5 \mathrm{~g} \mathrm{C} \mathrm{g}^{-1}$, with a relative standard error of $\pm 2 \%$, seems appropriate as a good assumption for mean carbon content (Fig. 4).

\subsection{Deadwood}

Germany's estimates of carbon stocks and carbon-stock changes, in deadwood, were carried out using NFI data from 2002 and 2012, the 2008 Inventory Study, and the 2017 carbon inventory (Kandler 2009; Kändler and Bösch 2013). Under forest land remaining forest land, the changes in Germany's deadwood carbon stocks are calculated with the stock-difference method. The annual carbon stock change in deadwood was calculated using the IPCC 2006, Ch 2, Eq. 2.19 below;

$$
\Delta C_{F F_{D W}}=\frac{A *\left(B_{t_{2}}-B_{t_{1}}\right)}{T} C
$$

where $B G B$ is the annual change in carbon stocks in deadwood, on forest land remaining forest land ( $\mathrm{C} \mathrm{ha}^{-1}$ ), $A$ is the area (ha), $B_{t_{1}}$ are the deadwood stocks at time $t 1$ (beginning of the period) for forest land remaining forest land, $B_{t_{2}}$ is the deadwood stocks at time (end of the period) for forest land remaining forest land ( $\left.\mathrm{C} \mathrm{ha}{ }^{-1}\right), T=\left(t_{2}-t_{1}\right)$ is 


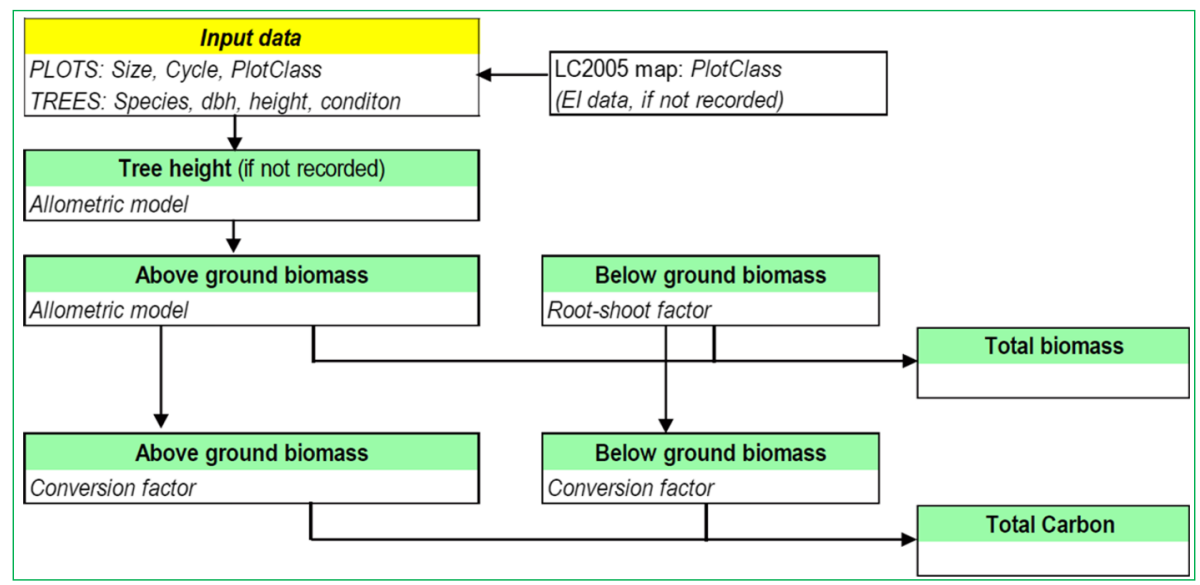

Fig. 4 Summary of tree carbon computing steps applied by Uganda to get the total carbon; source (FREL 2018)

the time period between the two estimates (a), and $C F$ is the carbon conversion factor (IPCC default value $=0.5$ ). Calculated annual carbon stock changes in deadwood on both land converted to forest land and forest land remaining forest land were both calculated using Eq. (12). Uganda did not report any changes in deadwood carbon stocks on forest land remaining forest land. The country uses the tier 1 assumption that deadwood carbon stocks are at equilibrium. The collection of standing and fallen deadwood data in the forest inventories has started with the hope of improving subsequent future GHG inventories (MWE 2019).

\subsection{Litter}

Germany calculates carbon stock changes in litter using the stock-difference method under forest land remaining forest land with the tier 2 method (IPCC 2006, Ch 2, Eq. 2.19). This is similar to the stock-difference method in Eq. (12) above. The only difference is in the $\mathrm{CF}$ of dry matter for litter (default $=0.37$ ) which is different for deadwood. For land converted to forest land, the carbon-stock equation (IPCC 2006, Ch 2, Eq. 2.23) from the guidelines is used. This methodology requires the derivation of the annual rate of carbonstock change. That rate is calculated from average litter stocks under equilibrium conditions and the transition period required for litter stocks to develop following afforestation (Eq. 13).

$$
\Delta C_{D O M}=\frac{\left(C_{n}-C_{o}\right) * A_{o n}}{T_{o n}}
$$

where $\Delta C_{D O M}$ is the annual change in carbon stocks in deadwood or litter (tonnes $\mathrm{C}$ year ${ }^{-1}$ ); $C_{o}$ is the litter stock, under the old land-use category (tonnes $\mathrm{C} \mathrm{ha}^{-1}$ ); $C_{n}$ is the litter stock, under the new land-use category (tonnes $\mathrm{C} \mathrm{ha}^{-1}$ ); $A_{o n}$ is the area undergoing conversion from old to new land-use category (ha); and $T_{\text {on }}$ is the time period of the transition from old to new land-use category (years). The tier 1 default is 20 years for carbon stock increases and 1 year for carbon losses. To estimate changes in litter carbon stocks, Uganda applied the IPCC 
default values for tropical broadleaf and needle leaf forests to the relevant forest types (IPCC 2006, Vol 4, Ch 2, Table 2.2). For land use conversion involving forest lands, Uganda applied the tier 1 equation (IPCC 2006, Ch 2, Eq. 2.23) and default values for litter (MWE 2019).

\subsection{Soil carbon}

Emissions from Germany's forest soils were estimated via the stock-difference method. Data from the National Forest Soil Inventory-I (NFSI-I) and the National Forest Soil Inventory-II (NFSI-II) were used (Baritz and Strich 2000; Grüneberg et al. 2014). The NFSI-I was carried out from 1987 to 1992, while the NFSI-II was carried out from 2006 to 2008. Uganda is in the process of updating its soil profile and developing a soil inventory. The National Agricultural Research Organisation (NARO) worked on Uganda's soil types. NARO related the soil types to IPCC tier 1 categorization by applying IPCC default values for carbon stocks. Land use stock change factors were used to estimate changes in mineral soil carbon.

\subsubsection{Mineral soils}

Germany uses the IPCC 2006, Ch 2, Eq. 2.25 as a tier 2 methodology to calculate carbon stock changes in mineral soils under forest land remaining forest land. Carbon stocks and carbon-stock changes in mineral soils were up-scaled based on the NFSI-I and NFSI-II (Grüneberg et al. 2014). With the available data, the changes in mineral soils were calculated, for both inventories. The resulting upscaling for the entire national territory yielded a mean annual increase in carbon stocks in mineral soils. The assumption is that this trend also continued in the period 2007 to 2017. This is because the goal of the NFSIs is to generate reliable data on the current state and changes in forest soils and selected features of the forests based on a systematic $8 \times 8 \mathrm{~km}$ grid and a repetition of the inventory every 15 years (Wellbrock and Bolt 2019).

$$
\begin{gathered}
\Delta C_{\text {Mineral }}=\frac{\left(\operatorname{SOC}_{0}-S O C_{(0-T)}\right)}{D} \\
S O C=\sum_{c, s, i}\left(\operatorname{SOC}_{R E F_{c, s, i}} * F_{L U_{c, s, i}} * F_{M G_{c, s, i}} * F_{I_{c, s, i}} * A_{c, s, i}\right)
\end{gathered}
$$

(Note: $\mathrm{T}$ is used in place of $\mathrm{D}$ in this equation if $\mathrm{T}$ is $\geq 20$ years).

where $\Delta C_{\text {Mineral }}$ is the annual change in carbon stocks in mineral soils (tonnes $\mathrm{C}$ year ${ }^{-1}$ ), $S O C_{0}$ is the soil organic carbon stock in the last year of an inventory time period (tonnes C), $S O C_{(0-T)}$ is the soil organic carbon stock at the beginning of the inventory time period in tonnes $\mathrm{C}$, and $D$ is the time dependence of stock change factors which is the default time period for transition between equilibrium SOC values (years). This period is commonly 20 years but depends on assumptions made in computing the factors.

For land converted to forest land, similar to forest land remaining forest land, the carbonstock change is calculated using the IPCC 2006, Ch 2, Eq. 2.25. The carbon stocks and their changes were derived based on inventory data (Grüneberg et al. 2014). Mineral soil was sampled at depth ranges of 0-5 cm, 5-10 cm, and 10-30 cm. An area-referenced approach, with strata formation, was used for calculation of carbon stocks and of their changes between the two inventory time points. The basis for the formation of area-relevant strata consisted of the 72 legend units used in the soil map for Germany "Bodenübersichtskarte der Bundesrepublik Deutschland 1:1.000.000" (BÜK 1000). That source describes the dominant 
soil types, and parent material for soil formation, according to the German soil system of the Geological district offices of the Geologische Landesämter and FAO (Batjes 1997).

\subsubsection{Organic soils}

Areas with organic soils in Germany were determined via a geo-referencing procedure, with an overlay between the organic soils map (Roßkopf et al. 2015) and ATKIS® data (Meinel and Knop 2008). In the process, drained and non-drained organic soils were differentiated. Those annual emissions are being reported for all years since the relevant conversions.

\subsection{Emissions from organic soils}

$\mathrm{CO}_{2}, \mathrm{~N}_{2} \mathrm{O}$, and $\mathrm{CH}_{4}$ emissions from organic soils are reported in the land-use categories forest land, cropland, grassland, woody grassland, terrestrial wetlands, and settlements. Reporting also covers $\mathrm{CH}_{4}$ emissions from drainage ditches, as well as carbon losses in connection with dissolved organic carbon (DOC) (Tiemeyer et al. 2020a, b). In Germany, the majority of organic soil areas are drained. Emissions are calculated by multiplying the peatland areas per sub-category by pertinent use-specific EFs. For land-use changes, the EF for the final category is used right away:

$$
E C_{\text {orgsoil }}=\sum_{n=1}^{7}\left(A_{n} * E F_{n}\right)
$$

where $E C_{\text {orgsoil }}$ is the carbon emissions from organic soils in a land-use category (kt C), $A_{n}$ is the peatland area subject to a certain land use (kha), $E F_{n}$ is the land-use-specific emission factor ( $\mathrm{t} \mathrm{Cha} \mathrm{h}^{-1} \mathrm{a}^{-1}$ ), and $n$ is the conversion categories or remaining categories.

\subsubsection{Organic soil emission factors}

The EFs for Germany were developed in keeping with the 2013 IPCC Wetlands Supplement (Hiraishi et al. 2014). The EFs for $\mathrm{CO}_{2}$ from soils $\left(\mathrm{CO}_{2}-\mathrm{C}\right.$ on-site), $\mathrm{CH}_{4}$ from soils $\left(\mathrm{CH}_{4}\right.$ land), and $\mathrm{N}_{2} \mathrm{O}$ were developed from national annual measurements (Tiemeyer et al. $2020 \mathrm{a}, \mathrm{b})$. For $\mathrm{CO}_{2}$ from dissolved organic carbon and $\mathrm{CH}_{4}$ from drainage ditches $\left(\mathrm{CH}_{4}\right.$ Ditch), the default from the 2013 IPCC Wetlands Supplement (Hiraishi et al. 2014) was used. Carbon emissions from Uganda organic soils were computed using IPCC 2006, Ch 2, Eq. 2.26. $\mathrm{CO}_{2}$ emissions from organic soils were estimated as a factor of land area affected and IPCC default emission factors;

$$
L_{\text {Organic }}=A * E F
$$

where $A$ is the land area of drained organic soil (or cultivated) and $E F$ is the emission factor of organic soils based on climate type.

\subsection{Wildfires}

Germany's GHG emissions arising from wildfires were calculated using the IPCC 2006, Ch 2, Eq. 2.27. Uganda is yet to estimate emissions from wildfires and is currently using coarse estimates from Moderate Resolution Imaging Spectroradiometer (MODIS) 
data. The initial step will involve the use of the same equation (Eq. 17) to determine its emissions.

$$
L_{\text {fire }}=A * B * C * D * 10^{-6}
$$

where $L_{\text {fire }}$ is the quantity of GHG (t) released via fire, $A$ is the wildfire burned area (ha), $B$ is the mass of fuel present on the relevant site (biomass) $\left(\mathrm{kg}_{\mathrm{dry}}\right.$ matter $\left.\mathrm{ha}^{-1}\right), C$ is the combustion efficiency, and $D$ is the emission factor $\left(\mathrm{g}\left(\mathrm{kg}_{\text {dry matter }}\right)^{-1}\right)$.

\subsection{Uncertainty analysis and time-series consistency}

In calculation and aggregation of uncertainties, Germany's activity data and EFs are converted into uncertainties for emissions and then aggregated (UBA 2017). Uncertainties are aggregated once per year, at the end of the report-preparation cycle for the current report year. The aggregated uncertainties serve as a basis for expanded identification of key categories (tier 2 key categories determination). In Germany, various uncertainties have to be taken into account in the calculation of carbon stocks. The actual uncertainties, however, have to be approximated, with the help of pragmatic approaches. The uncertainties highlighted are included in a total-error budget for the LULUCF sector within Germany's National Inventory Report (NIR). Uganda's overall inventory uses mostly default IPCC ranges to estimated uncertainty within the 2006 IPCC software tool. However, these uncertainties are yet to be reported officially in the NIR.

\subsection{Quality assurance (QA)/quality control (QC) and verification}

The QA/QC measures are carried out, in conformance with the QSE manual requirements (Döring et al.) by the relevant involved experts and the Single National Entity (SNE). For QA, detailed checklists and individual checks are used for review. Results are documented in keeping with the quality management guidelines of the TI. The TI's quality management for emissions-inventory preparation has been developed in conformance with the IPCC Guidelines (Eggleston 2006) and the QSE manual (Chapter 1.3.3). The SNE archives the TI checklists and other important QC documents required for external review. Complete error analysis is carried out for the LULUCF sector, and an attempt made to quantify all existing sources of error. This work includes error calculations relative to the forest categories, for biomass, deadwood, litter, mineral soils, organic soils and wildfires, $\mathrm{CO}_{2}$, $\mathrm{N}_{2} \mathrm{O}$, and $\mathrm{CH}_{4}$. The land-use matrix is checked for quality and then approved for emissions calculation. The calculations of emissions for annual land-use changes and the transition period are implemented step-by-step, in tabular form, based on the area data and emission factors/implied emission factors (IEF). The assessment focuses on the correctness of the calculations, consistency of the time series, and consistency with the calculations of the previous year. Quality controls that were applied in Uganda's GHG entailed generic quality checks associated with calculations, processing of data, completeness, and documents relevant to the inventory. With support from the REDD + program, the forestry sector recently introduced QC protocols in data collection processes for the estimation of forest carbon stocks. Land use land cover mapping has also introduced map accuracy assessment as a quality control protocol. Discussions on data flow processes and QA processes in all source 


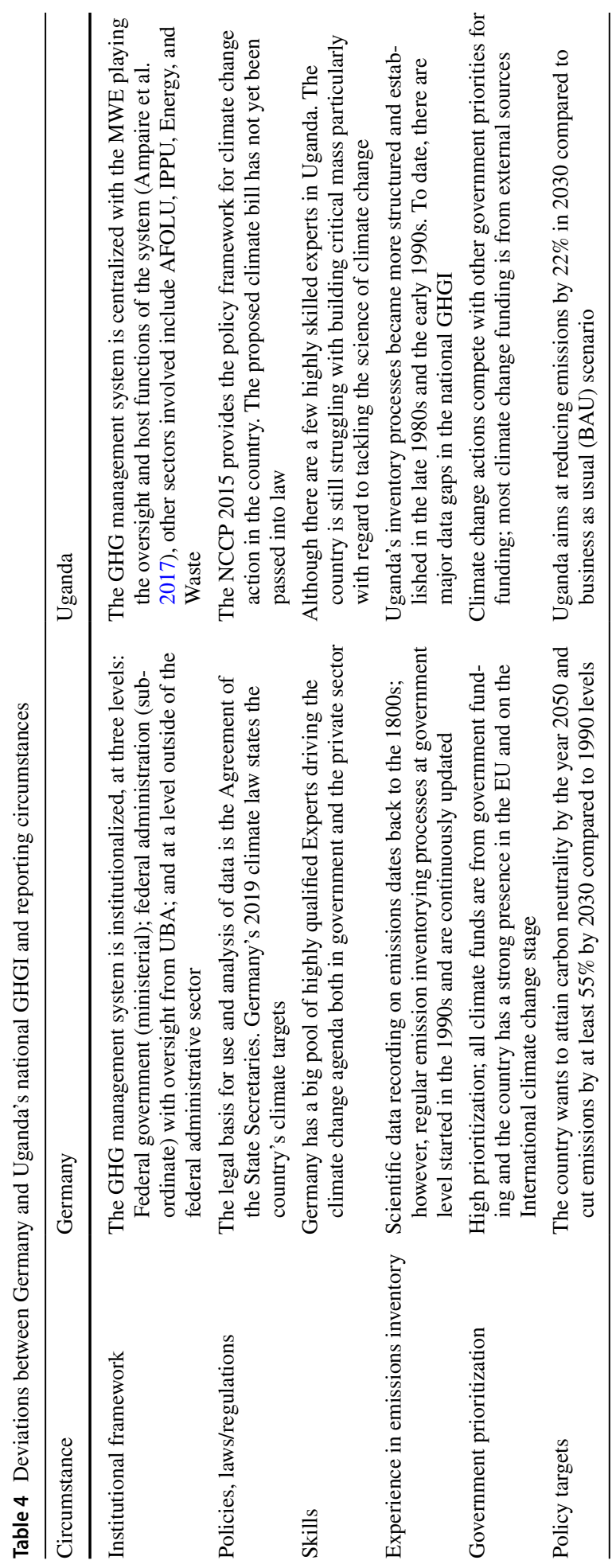


categories are still ongoing. Currently, Uganda's QA is outsourced and the country is yet to establish a proper QA/QC system, let alone develop a QA/QC plan (Table 4).

\section{Discussion}

There are insinuations that the UNFCCC Annex-based classification system generally seems not to be a good reference point for differentiation between developed and developing countries (Voigt and Ferreira 2016; Castro et al. 2011; Stone 2004). This inference has driven some studies to analyze the importance of parties developing a dynamic and functional national GHG system (Lim et al. 1999; Romijn et al. 2012; Russell-Smith et al. 2009; Scott et al. 2016). Such a system will help the country to track the progress of national emissions and improve accuracy in emissions inventorying and reporting. Germany as a nation has a long history of collecting data on air pollution and emissions. However, a number of fundamental changes had a significant impact on the inventory and ultimately the recorded trends. The periods and aftermath of the two world wars (1914-1918 and 1939-1945 respectively) recorded decreases in Germany's emissions (Granier et al. 2011). This was in part due to the disruption in industrial production processes and reduced vehicle movements. When Germany began stabilizing, corresponding and consistent increments in emissions were recorded and the trends peaked in 1979 (Kerstine et al. 2020). It was in the 1980s and early 1990s that Germany started playing a bigger role in the climate change arena within Europe (Sprinz and Wahl 1998; Zito 2000). In this same period, Uganda was at her infancy in terms of engagement within the climate change arena. The country started establishing policy, legal, and institutional frameworks and joined the UNFCCC in 1992. A decade later in 2002, Uganda ratified the KP (MWE 2019). Uganda is, therefore, still relatively new in the climate change science arena. This is exemplified by the ongoing technical and capacity challenges in meeting her international obligations. Germany through the Deutsche Gesellschaft für Internationale Zusammenarbeit GmbH (GIZ) has played a critical role in Uganda's technical development landscape. Technical assistance and skills enhancement of the country's work base has been offered through a number of projects implemented over the years. GIZ has been in Uganda since 1964, 2 years after Uganda gained independence. GIZ projects over the years have focused on different development aspects and more recently on climate change mitigation and adaptation. Projects like climate-smart livestock systems, global carbon markets, and rural electrification have been implemented. These projects have made tremendous contributions in the creation of a climate change skill base in the country. The global carbon market project is focusing on activities related to the transfer of skills, approaches, and experiences. It is also trying to ensure continuity of ongoing Clean Development Mechanism (CDM) projects (GIZ 2018), while contributing to the design of Article 6 through piloting activities. The project is also supporting Uganda and other East African countries to utilize carbon mechanisms for their NDC implementation. Germany as a country is one of the few parties that have experienced a reduction in net emissions from the LULUCF sector. A closer look at the national statistics shows that the forestry sector is one of the sectors responsible for this reduction. Carbon sequestration within forest biomass has, therefore, played a major role. It has led to a 1.6\% total reduction in emissions as of the year 2015 (UBA 2017). This positive trend has been largely achieved due to a strong policy and regulatory framework (Jaggard 2007) governing all involved sectors. Germany also has a long history of proper forest management and a deep-rooted national desire for environmental protection and conservation. The 
availability of long-term consistent, quality data and proper collection and archiving (Krug 2018) processes have helped the country to track past and model future emission trends. This has been a backbone in the formulation of climate change policies and action plans for the country. A highly skilled and technical base oversees and drives the science behind the national climate change agenda. Uganda's emissions have had a steady rise, increasing from 53 thousand Gg tonnes in 2005 to close to 90 thousand Gg tonnes in 2015. The Agriculture, Forestry and Other Land Use (AFOLU) sector has remained the most significant source accounting for over $86 \%$ of the emissions followed by the energy sector accounting for $10.8 \%$ (MWE 2019). Uganda has, within her limited resource envelop, tried to enhance her mitigation actions as required by the UNFCCC. The country participated effectively in the KPs CDM and initiated implementation of the developed Nationally Appropriate Mitigation Action projects. Recently, Uganda developed and submitted her NDCs based on the policy priorities in the Second National Development Plan. The specific NDC mitigation commitment is a $22 \%$ emission reduction by 2030 compared to the BAU scenario to be achieved through nationally and internationally supported mitigation actions. The common denominator for sustained, effective, and accurate reporting on all the above processes is a fully established and functional GHGI system. However, as is the case in several developing countries, emission inventorying in Uganda is still a work in progress (DeFries et al 2007). The development of a quality and sustainable national GHGI system process is still encountering significant constraints (Lund 2006). This is compounded by the fundamental challenges in capacity building and technology transfer that have affected timely and consistent reporting on LULUCF sector emissions (Mugagga et al. 2017). Challenges like funding for data collection, absence of data sharing agreements, insufficient documentation of methods, and data sources used in previous inventories are still existent. These challenges are undermining the effective operationalization of the GHGI (DeFries et al. 2007).

Germany's inventory system and policy framework have enhanced transparency, and consistency, a requirement for all parties under the transparency framework of the PA. Their CSE helps in checking parameters such as quality, completeness, and accuracy of the data (Schlenzig 2002). The legal basis for use and analysis of data is the Agreement of the State Secretaries. Germany managed after many years of deliberations between the different ministries and federal states (Koch 2010) to pass the 2019 climate law (Kerstine et al. 2020). The law states the country's climate targets and its desire to attain carbon neutrality by the year 2050. Germany also intends to cut emissions by at least $55 \%$ by 2030 compared to 1990 levels. Germany was still behind in its 2020 targets, but the 2019 corona disease pandemic might have lowered the emissions trajectory. The final official calculations will confirm or refute this deduction. Data access continues to be problematic in Uganda, and the biggest challenge is the unavailability of accurate and complete activity data (Lwasa 2017). This has led to a great deal of uncertainty about the reliability of emission estimations from deforestation and forest degradation (Köhl et al. 2009). Other country-specific challenges include lack of data sharing agreements, difficulty in retaining capacity and expertise, and insufficient documentation of methods and data sources that were used in previous GHGIs. Strengthening of sector teams and the MWE team is critical for establishing a sustainable national GHGI management system (MWE 2019). The current land law recognizes competing interests of lawful/bonafide occupants and registered land owners on the same piece of land which is a trigger of conflicts, grievances and a challenge to forest management (NFA 2009). The country needs to come up with harmonized laws for proper governance and management of forestry resources.

Deforestation and forest degradation are the biggest drivers of emissions in Uganda's forestry sector. In Germany's case, forests are more sustainably managed and not exposed 
to deforestation in the traditional sense. Over $90 \%$ of Uganda's energy is biomass-based which means that forests contribute tremendously in powering the country's economy (Dastan et al. 2017). It is estimated that $50 \%$ of all fuelwood and wood needed for charcoal production is harvested from non-forest land and the balance from forest land. These dynamics greatly influence the applied inventory methodologies as evidenced by the two countries' differing approaches to accounting for biomass and carbon stock changes (Table 5). Generally speaking, Germany applies the stock-difference method (Eq. 4), while Uganda employs the gain-loss method (Eq. 5) in the same land-use category (Table 5). This said, Uganda is still struggling with incomplete datasets and yet this approach, which compares annual removals of the various forms of wood extraction (timber, pole, firewood, etc.), requires availability of said datasets.

This lack of country-level data has necessitated the use of global and regional allometric equations like the use of IPCC default values. The country is also still struggling with building critical mass particularly with regard to tackling climate change science aspects (Ampaire et al. 2017). Going forward, the country needs to prioritize skills development and capacity building as a mechanism of enhancing GHG reporting and inventory processes. Future and deeper collaborations with Germany through GIZ will play a vital and critical role in the country's development trajectory. Although the equation of Cheve et al. (2014) was used due to its comparability to local equations and ease of execution, the need to develop country-specific equations to enhance reporting accuracy still exists. Uganda does not have allometric equations for analyzing BGB emissions; the country applies the default 2006 IPCC root-to-shoot conversion factor of 0.24 to AGB. In a drive to improve inventory accuracy, the country is currently looking into applying different root-to-shoot ratios based on forest types. The target is to use more accurate data to inform the current working draft of the NIR. Datasets on lying and standing deadwood have been collected. However, Uganda's NFA believes that this data is not adequately representative to be used for emission estimations. The litter pool is considered insignificant based on the guidelines' default range of approximately $1.4-3.5 \%$ of AGB and BGB carbon stocks in tropical high forests. At the moment, Uganda's litter percentages are lower than the stated range, and there are currently no plans to collect data on the litter pool.

While in other countries "prescribed burning" is an accepted method for clearing land/ managing ecosystems, no prescribed/controlled burning is carried out in Germany's forests. The $\mathrm{CO}_{2}$ emissions resulting from biomass combustion (wildfire), and calculated using IPCC 2006, Ch 2, Eq. 2.27, are taken into account implicitly. The calculation is derived from the burnt area and the mass of fuel available for combustion. This is quite common across Europe where wildfires are mainly monitored remotely (San-Miguel-Ayanz et al. 2012). Germany, besides remotely sensed data, uses annual forest fire statistics from the Federal Office for Agriculture and Food to calculate wildfire emissions. Wildfires constitute one of the key drivers of deforestation and forest degradation in Uganda (Mwangi et al. 2018); however, the country does not have ground data on burning. Uganda is currently using MODIS fire datasets from the University of Maryland (MWE 2019); however, estimates for biomass burning from these datasets have high uncertainty levels. Biomass burning is a key category in Uganda's GHGI. Data collection protocols within Uganda's NFA for estimating areas of biomass burning need to be improved. Unlike Germany, key forestry management institutions in Uganda are grossly under-resourced (Kaggwa et al. 2009). These institutions include the NFA, National Environment Management Authority (NEMA), UWA, and district forestry offices. These inadequacies in human and financial resources have also affected their ability to effectively manage forests. The conflicting mandates of key government institutions have also undermined effectiveness. This is best illustrated by the conflicting 


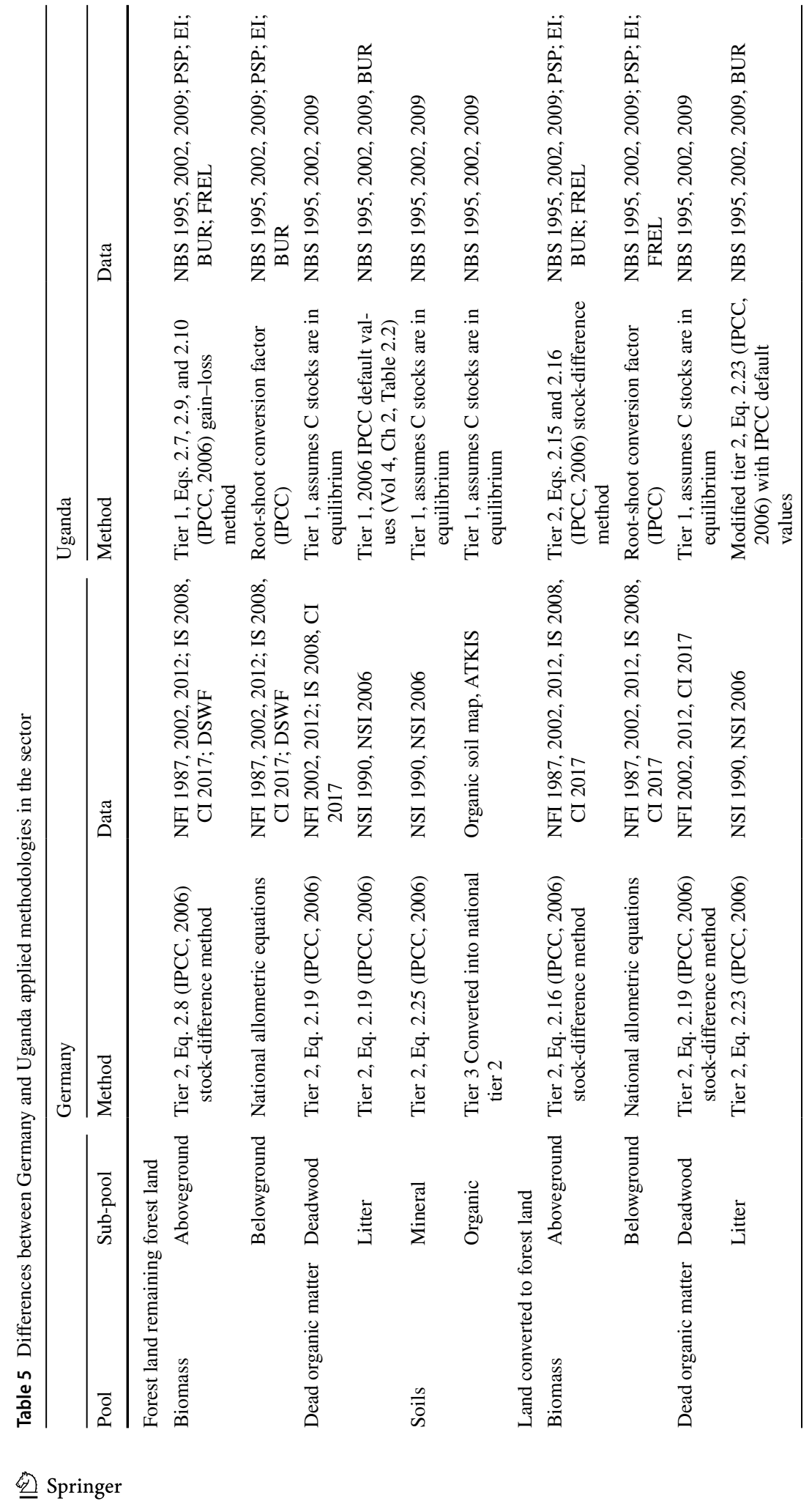




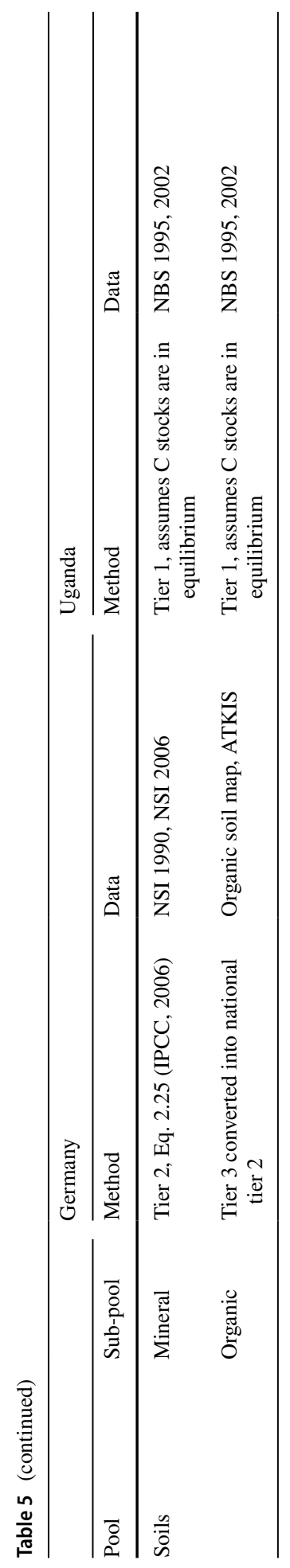


roles of NFA and the Uganda Land Commission. The National Forestry and Tree Planting Act, 2003, gives NFA the mandate to manage central forest reserves. However, Article 239 of the Constitution of Uganda, 1995, and Sect. 49 of the Land Act (Cap 227) deviate. They empower the Uganda Land Commission to manage all government land including that occupied by central forest reserves (Turyahabwe and Banana 2008). This has resulted in the two government institutions clashing over the control of central forest reserves (Nsita et al. 2017). Germany's governance and management systems are well streamlined from the federal level down to local levels. This alignment has enabled the country to come up with unified strategies and effective management of forestry resources. This has naturally translated to better responses to climate change impacts.

\section{Conclusion}

Continuous review and improvement of the GHG reporting systems increases their scope and efficiency. It has taken Germany a while to come up with stable inventorying and reporting structures. Uganda should, therefore, continue to pursue inventory improvements, knowing that national inventory and reporting systems get better over time. The GHG management system of Germany is institutionalized, at three different levels inclusive of the local level; however, all levels are well integrated and the system is efficient. Uganda chose a centralized GHG management system as the country's preferred model. However, the different actors at different levels should be integrated into the process for better data and knowledge acquisition. District local governments should be given a specific role to play in the management of central forest reserves. This will ultimately improve the collection and inventorying of local data to be used in the GHGI process. The current situation has alienated district local governments from the management of central forest reserves thus accelerating deforestation and forest degradation. The approval processes in Germany can be a bit tedious and time-consuming due to the different reporting levels. The Agreement of the State Secretaries was formulated as a quick and legal basis for use and analysis of data. This has worked quite well for the institutions involved in climate change reporting. Uganda should borrow a leaf from Germany. Although the 2005 National Climate Change Policy provides the policy framework for climate change action, the country is yet to get a climate change law. The institutions involved in GHGI reporting can formulate data sharing agreements and memorandums of understanding (MoUs). These documents can form the operational base for coordination and collaboration with regard to GHGI management and reporting. Germany has a big pool of highly qualified experts driving the climate change agenda in government and the private sector. This came as a result of government prioritization of climate actions, the involvement of the private sector, and focused research. Uganda should, as a concerted drive to increase on the skill base, also prioritize the climate change agenda. Availing more resources towards climate-focused research and mobilizing all stakeholders including the private sector to come on board are crucial. Due to these limitations, Uganda is using the tier 1 methodological approach for GHG emissions inventory, and as a developing country. Data and information collection is still a huge challenge when compiling the GHGI making the use of higher tier level methods difficult. Going forward, it will be imperative for the GHG preparation process in Uganda to become more consolidated and institutionalized. This will work as a catalyzing mechanism that enhances the timely delivery of emissions updates and the fulfillment of national reporting obligations. Additionally, this would result in increased efficiency in 
the use of available resources. The lack of standardized data reporting formats has posed challenges. This has led to incoherencies in the information reported through various institutional channels. National reporting channels should also be streamlined for effective data capture and use. Uganda can develop and implement a common information-sharing system/platform similar to the LULUCF-WIKI of Germany. This tool can be used to generate, analyze, share, and archive data as a way to offset the impact of staff turnover. These efforts should build on the best practices and lessons learned from efforts already undertaken to document and process data. Uganda should consider setting up enforcement provisions that identify consequences for entities that are non-compliant. Further stakeholder engagement and awareness-raising on data collection and the importance of the GHGI system will be crucial. Broader government climate change policy efforts and the international agenda should be pursued. Germany is using higher tiers; however, we recommend that the next NIR should contain the planned improvements of using the developed country-specific biomass functions by Röhling et al. (2019). These functions, which are more representative of the country's scenario, can be used to derive BGB for birch, oak, and pine tree species. Germany needs to closely refer to plans specified within its inventory plan (IP) located in the LULUCF WIKI and the NIR. It contains the institutional and official/formal procedures to handle improvements in the inventory. As highlighted in the IP, Germany needs to expedite the planned improvements particularly with regard to time-series consistency and increased transparency/comparability of its reporting. The country should also continuously highlight and update the key assumptions underlying its assessment of the insignificance of categories for which emissions are not estimated. Uganda's use of the 0.24 IPCC default value as the ratio of BGB to AGB for estimating emissions from deforestation is a good starting point. However, it is inaccurate to use the same value for all forest types. Therefore, the authors recommend this as an area for future technical improvement. Specifically, to apply a different root-shoot ratio for each forest type and/or forest substratum to improve the accuracy of the estimations. Continuing efforts to update and improve the accuracy of activity data to further reduce uncertainties is important for both countries. Going forward, it will be imperative for the two countries to emphasize emission inventories from deadwood, soils, and forest fires.

Abbreviations AFOLU: Agriculture, Forestry and Other Land Use; AGB: Aboveground biomass; BAU: Business as usual; BGB: Belowground biomass; BUR: Biennial update reports; CCD: Climate Change Department; CDM: Clean Development Mechanism; CFI: Continuous forest inventory; CH4: Methane; $\mathrm{CO}_{2}$ : Carbon dioxide; CSE: Central System on Emissions; DBH: Diameter at breast height; DOC: Dissolved organic carbon; EF: Emission factor; EI: Exploratory Inventory; Eq: Equation; GHG: Greenhouse gas; GHGI: Greenhouse Gas Inventories; GIZ: Deutsche Gesellschaft für Internationale Zusammenarbeit GmbH; IEF: Implied emission factors; IP: Inventory plan; IPCC: Intergovernmental Panel on Climate Change; KP: Kyoto Protocol; LULUCF: Land Use, Land-Use Change, and Forestry; MODIS: Moderate Resolution Imaging Spectroradiometer; MoU: Memorandum of Understanding; MWE: Ministry of Water and Environment; N2O: Nitrous oxide; NAMA: Nationally Appropriate Mitigation Action; NARO: National Agricultural Research Organisation; NASA: National Aeronautics and Space Administration; NBS: National Biomass Studies; NCCP: National Climate Change Policy; NDC: Nationally Determined Contribution; NEMA: National Environment Management Authority; NFA: National Forest Authority; NFI: National Forest Inventories; NFSI: National Forest Soil Inventory; NIR: National Inventory Report; PA: Paris Agreement; PSP: Permanent Sample Plots; QA/QC: Quality assurance/quality control; QSE: Quality system of emissions; SNE: Single National Entity; UBA: German Environment Agency; UNFCCC: United Nations Framework Convention on Climate Change; UWA: Uganda Wildlife Authority

Acknowledgements This work is part of the International Climate Protection Fellowship which facilitated the collaboration between Germany's Thünen Institute of Forest Ecosystems and Uganda's Ministry of Water and Environment, aimed at knowledge exchange and collaboration for effective Greenhouse Gas Inventorying and management. The authors are grateful for the constructive feedback from colleagues on the draft manuscript. 
Author contribution MM led the development and production of the script. WS, KD, AB, MR, SR, and EA contributed substantially. All authors read and approved the final manuscript.

Funding Open Access funding enabled and organized by Projekt DEAL. This article is one of the outputs of the research funded by the Alexander von Humboldt Foundation.

Data availability The data supporting the conclusions of this article are available at the respective links listed in the references.

Code availability Not applicable.

\section{Declarations}

Competing interests The authors declare no competing interests.

Open Access This article is licensed under a Creative Commons Attribution 4.0 International License, which permits use, sharing, adaptation, distribution and reproduction in any medium or format, as long as you give appropriate credit to the original author(s) and the source, provide a link to the Creative Commons licence, and indicate if changes were made. The images or other third party material in this article are included in the article's Creative Commons licence, unless indicated otherwise in a credit line to the material. If material is not included in the article's Creative Commons licence and your intended use is not permitted by statutory regulation or exceeds the permitted use, you will need to obtain permission directly from the copyright holder. To view a copy of this licence, visit http://creativecommons.org/licenses/by/4.0/.

\section{References}

Ampaire EL, Jassogne L, Providence H, Acosta M, Twyman J, Winowiecki L, Van Asten P (2017) Institutional challenges to climate change adaptation: a case study on policy action gaps in Uganda. Environ Sci Policy 75:81-90

Ari I, Sari R (2017) Differentiation of developed and developing countries for the Paris Agreement. Energ Strat Rev 18:175-182

Avitabile V, Herold M, Henry M, Schmullius C (2011) Mapping biomass with remote sensing: a comparison of methods for the case study of Uganda. Carbon Balance Manage 6:7

Baritz R, Strich S (2000) Forests and the national greenhouse gas inventory of Germany. COST E21 Workshop. Contribution of forests and forestry to mitigate greenhouse effects. Joensuu (Finland). 28-30 Sep 2000. Biotechnologie, Agronomie, Société et Environnement

Batjes N (1997) A world dataset of derived soil properties by FAO-UNESCO soil unit for global modelling. Soil Use Manag 13:9-16

Beck S, Kuhlicke C, Görg C (2009) Climate policy integration, coherence, and governance in Germany. PEER Climate Change Initiative-Project 2: "Climate policy integration, coherence, and governance". UFZ-Bericht

Bolte A, Hertel D, Ammer C, Schmid I, Nörr R, Kuhr M, Redde N (2003) Freilandmethoden zur untersuchung von baumwurzeln. Forstarchiv 74:240-262

Braun C, Merk C, Pönitzsch G, Rehdanz K, Schmidt U (2018) Public perception of climate engineering and carbon capture and storage in Germany: survey evidence. Climate Policy 18:471-484

Bulkeley H, Kern K (2006) Local government and the governing of climate change in Germany and the UK. Urban Stud 43:2237-2259

Burschel P, Kürsten E, Larson BC (1993) Die Rolle von Wald und Forstwirtschaft im Kohlenstoffhaushalt-Eine Betrachtung für die Bundesrepublik Deutschland. Forstliche Forschungsberichte München, $135 \mathrm{~S}$

Buyinza J, Tumwebaze S, Namaalwa J, Byakagaba P (2014) Above-ground biomass and carbon stocks of different land cover types in Mt. Elgon, Eastern Uganda

Castro P, Hörnlein L, Michaelowa K (2011) Path dependence of negotiation structures in international organizations: the impact of annex I membership on discussions within the UNFCCC. CIS Working Paper

Change I (2006) 2006 IPCC guidelines for national greenhouse gas inventories 
Chave J, Réjou-Méchain M, Búrquez A, Chidumayo E, Colgan MS, Delitti WB, Duque A, Eid T, Fearnside PM, Goodman RC (2014) Improved allometric models to estimate the aboveground biomass of tropical trees. Glob Change Biol 20:3177-3190

Cohen G, Jalles JT, Loungani P, Marto R (2018) The long-run decoupling of emissions and output: evidence from the largest emitters. Energy Policy 118:58-68

Dastan B, Antwi DS, Petra H, Vaclav K (2017) Firewood and charcoal production in Uganda. Int Multidiscip Sci GeoConference SGEM 17:521-527

DeFries R, Achard F, Brown S, Herold M, Murdiyarso D, Schlamadinger B, de Souza Jr C (2007) Earth observations for estimating greenhouse gas emissions from deforestation in developing countries. Environ Sci Policy 10:385-394

Den Elzen M, Höhne N (2008) Reductions of greenhouse gas emissions in Annex I and non-Annex I countries for meeting concentration stabilisation targets. Springer

Dietrich H, Wolf T, Kawohl T, Wehberg J, Kändler G, Mette T, Röder A, Böhner J (2019) Temporal and spatial high-resolution climate data from 1961 to 2100 for the German National Forest Inventory (NFI). Ann for Sci 76:6

Drexhage M, Colin F (2001) Estimating root system biomass from breast-height diameters. Forestry 74:491-497

Dunger K, Petersson SH-O, Barreiro S, Cienciala E, Colin A, Hylen G, Kusar G, Oehmichen K, Tomppo E, Tuomainen T (2012) Harmonizing greenhouse gas reporting from European forests: case examples and implications for European Union level reporting. For Sci 58:248-256

Eggleston S (2006) Estimation of Emissions from CO2 Capture and Storage: the 2006 IPCC Guidelines for National Greenhouse Gas Inventories, Presentation at the UNFCCC workshop on carbon dioxide capture and storage

Eggleston S (2008) Overview of relevant methodologies in IPCC Guidelines and Good Practice Guidance, Presentation at the UNFCCC workshop on Methodological Issues relating to Reducing Emissions from Deforestation and Forest Degradation in Developing Countries, Tokyo, pp. 24-27

FREL (2018) Proposed forest reference emission level for Uganda. 2018. Ministry of Water and Environment. https://www.mwe.go.ug/library/uganda-forest-reference-emission-level. Accessed 24 Jan 2021

GIZ (2018) Global Carbon Market, Deutsche Gesellschaft für Internationale Zusammenarbeit (GIZ). https:// www.giz.de/en/worldwide/42190.html. Accessed 24 Jan 2021

Granier C, Bessagnet B, Bond T, D’Angiola A, van Der Gon HD, Frost GJ, Heil A, Kaiser JW, Kinne S, Klimont Z (2011) Evolution of anthropogenic and biomass burning emissions of air pollutants at global and regional scales during the 1980-2010 period. Clim Change 109:163

Grüneberg E, Ziche D, Wellbrock N (2014) Organic carbon stocks and sequestration rates of forest soils in Germany. Glob Change Biol 20:2644-2662

Hake J-F, Fischer W, Venghaus S, Weckenbrock C (2015) The German Energiewende-history and status quo. Energy 92:532-546

Henry M, Maniatis D, Gitz V, Huberman D, Valentini R (2011) Implementation of REDD+ in sub-Saharan Africa: state of knowledge, challenges and opportunities. Environ Dev Econ 16:381-404

Hiraishi T, Krug T, Tanabe K, Srivastava N, Baasansuren J, Fukuda M, Troxler T (2014) 2013 supplement to the 2006 IPCC guidelines for national greenhouse gas inventories: wetlands. IPCC, Switzerland

Höhne N, Wartmann S, Herold A, Freibauer A (2007) The rules for land use, land use change and forestry under the Kyoto Protocol-lessons learned for the future climate negotiations. Environ Sci Policy 10:353-369

Jaggard L (2007) Climate change politics in Europe: Germany and the international relations of the environment. IB Tauris

Jänicke M (2010) German climate change policy. The European Union as a leader in international climate change politics 15,129

Johansson T, Hjelm B (2012) Stump and root biomass of poplar stands. Forests 3:166-178

Kaggwa R, Hogan R, Hall B (2009) Enhancing forests' contribution to growth, employment and prosperity. Environment and Natural Resources Report Series

Kandler G (2009) The design of the second German national forest inventory, In: McRoberts, Ronald E.; Reams, Gregory A.; Van Deusen, Paul C.; McWilliams, William H., eds. Proceedings of the Eighth Annual Forest Inventory and Analysis Symposium; 2006 October 16-19; Monterey, CA. Gen. Tech. Report WO-79. Washington, DC: US Department of Agriculture, Forest Service. 19-24

Kändler G, Bösch B (2013) Methodenentwicklung für die 3. Bundeswaldinventur: Modul 3 Überprüfung und Neukonzeption einer Biomassefunktion-Abschlussbericht. Tech Rep FVA-BW 2013:1-72. (In German) 
Kartha S, Erickson P (2011) Comparison of Annex 1 and non-Annex 1 pledges under the Cancun Agreements. Stockholm Environment Institute

Kerstine A, Freja E, Julian W (2020) Germany's greenhouse gas emissions and energy transition targets, Clean Energy Wire

Koch H-J (2010) Climate change law in Germany. J Eur Environ Plan Law 7:411-436

Köhl M, Baldauf T, Plugge D, Krug J (2009) Reduced emissions from deforestation and forest degradation (REDD): a climate change mitigation strategy on a critical track. Carbon Balance Manage 4:10

Krug JH (2018) Accounting of GHG emissions and removals from forest management: a long road from Kyoto to Paris. Carbon Balance Manage 13:1

Lahn B, Sundqvist G (2017) Science as a "fixed point"? Quantification and boundary objects in international climate politics. Environ Sci Policy 67:8-15

Lim B, Boileau P, Bonduki Y, Van Amstel A, Janssen L, Olivier J, Kroeze C (1999) Improving the quality of national greenhouse gas inventories. Environ Sci Policy 2:335-346

Lund HG (2006) Guide for classifying lands for greenhouse gas inventories. J Forest 104:211-216

Lwasa S (2017) Options for reduction of greenhouse gas emissions in the low-emitting city and metropolitan region of Kampala. Carbon Manag 8:263-276

Mbeva K, Pauw W (2016) Self-differentiation of countries' responsibilities. German Development Institute/ Deutsches Institut für Entwicklungspolitik (DIE)

McRoberts RE, Næsset E, Gobakken T (2018) Comparing the stock-change and gain-loss approaches for estimating forest carbon emissions for the aboveground biomass pool. Can J for Res 48:1535-1542

Meeus L, Azevedo I, Marcantonini C, Glachant J-M, Hafner M (2012) EU 2050 low-carbon energy future: visions and strategies. Electr J 25:57-63

Meinel G, Knop M (2008) Geobasisdaten in Deutschland-Verfügbarkeit und Qualitätsaspekte des ATKIS® Basis-DLM und der DTK25 (-V). na

Mugagga F, Nagasha B, Barasa B, Buyinza M (2017) The effect of land use on carbon stocks and implications for climate variability on the slopes of Mount Elgon, Eastern Uganda

Mutibwa PM (1992) Uganda since independence: a story of unfulfilled hopes. Africa World Press

Mwangi E, Cerutti P, Doumenge C, Nasi R (2018) The current state of Eastern Africa's forests

Mwanjalolo M, Bernard B, Paul M, Joshua W, Sophie K, Cotilda N, Bob N, John D, Edward S, Barbara N (2018) Assessing the extent of historical, current, and future land use systems in Uganda. Land 7:132

MWE (2015) Uganda's nationally determined contributions (NDC). https://unfccc.int/gcse?q=Uganda\% 20NDC. Accessed on 24 Jan 2021

MWE (2019) Uganda's First Biennial Update Report to the United Nations Framework Convention on Climate Change. Ministry of Water and Environment, Kampala. https://unfccc.int/gcse?q=\%20Uganda\% 20Biennial\%20Update\%20Report. Accessed on 24 Jan 2021

Namanya B (2008) Challenges to CDM implementation in Uganda: a critical analysis of legal and policy barriers. Int J Green Energy 5:255-267

Neubauer M, Demant B, Bolte A (2015) Einzelbaumbezogene Schätzfunktionen zur unterirdischen Biomasse der Wald-Kiefer (Pinus sylvestris L.). Forstarchiv 86(2):42-47

Neubauer M, Demant B, Bolte A (2015) Tree-based estimator for below-ground biomass of Pinus sylvestris L. Forstarchiv 86:42-47

NFA (2009) Uganda National Forest Authority. https://www.mwe.go.ug/sites/default/files/National\% 20Forest\%20Plan\%20Uganda.pdf. Accessed on 24 Jan 2021

Nick R, Ulf R (2018) A brief history of the German national reporting system on climate change. In: Matthias D, Oscar Z (eds) Deutsche Gesellschaft für Internationale Zusammenarbeit (GIZ) GmbH

Nsita S, Nakangu B, Banana A, MshaleB, Mwangi E, Ojwang D (2017) Forest tenure reform implementation in Uganda: current challenges and future opportunities. CIFOR

Pauw P, Mbeva K, van Asselt H (2019) Subtle differentiation of countries' responsibilities under the Paris Agreement. Palgrave Commun 5:86

Polley H, Hennig P, Kroiher F, Marks A, Riedel T, Schmidt U, Schwitzgebel F, Stauber T (2014) Der Wald in Deutschland: Ausgewählte Ergebnisse Der Dritten Bundeswaldinventur. Bundesministeriums für Ernährung und Landwirtschaft: Berlin, Germany

Prechtel A, von Lützow M, Uwe Schneider B, Bens O, Bannick CG, Kögel-Knabner I, Hüttl RF (2009) Organic carbon in soils of Germany: Status quo and the need for new data to evaluate potentials and trends of soil carbon sequestration. J Plant Nutr Soil Sci 172:601-614

Obergassel W, Arens C, Hermwille L, Kreibich N, Mersmann F, Ott HE, Wang-Helmreich H (2015) Phoenix from the ashes: an analysis of the Paris Agreement to the United Nations Framework Convention on Climate Change; part 1 
Röhling S, Dunger K, Kändler G, Klatt S, Riedel T, Stümer W, Brötz J (2016) Comparison of calculation methods for estimating annual carbon stock change in German forests under forest management in the German greenhouse gas inventory. Carbon Balance Manage 11:12

Röhling S, Demant B, Dunger K, Neubauer M, Oehmichen K, Riedel T, Stümer W (2019) Equations for estimating belowground biomass of Silver Birch, Oak and Scots Pine in Germany. iForest-Biogeosci For 12:166

Romijn E, Herold M, Kooistra L, Murdiyarso D, Verchot L (2012) Assessing capacities of non-Annex I countries for national forest monitoring in the context of REDD+. Environ Sci Policy 19:33-48

Roßkopf N, Fell H, Zeitz J (2015) Organic soils in Germany, their distribution and carbon stocks. Catena 133:157-170

Russell-Smith J, Murphy BP, Meyer CM, Cook GD, Maier S, Edwards AC, Schatz J, Brocklehurst P (2009) Improving estimates of savanna burning emissions for greenhouse accounting in northern Australia: limitations, challenges, applications. Int J Wildland Fire 18:1-18

San-Miguel-Ayanz J, Schulte E, Schmuck G, Camia A, Strobl P, Liberta G, Giovando C, Boca R, Sedano F, Kempeneers P (2012) Comprehensive monitoring of wildfires in Europe: the European forest fire information system (EFFIS), Approaches to Managing Disaster-Assessing Hazards, Emergencies and Disaster Impacts. IntechOpen

Schlenzig C (2002) The MESAP software for the German emission inventory. Proceedings Enviro-Info Vienna

Scott D, Hall CM, Gössling S (2016) A report on the Paris Climate Change Agreement and its implications for tourism: why we will always have Paris. J Sustain Tour 24:933-948

Sprinz DF, Wahl A (1998) Reversing course: Germany's response to the challenge of transboundary air pollution. Potsdam Inst. for Climate Impact Research

Stone CD (2004) Common but differentiated responsibilities in international law. Am J Int Law 98:276-301

Tiemeyer B, Freibauer A, Albiac-Borraz E, Augustin J, Bechtold M, Beetz S, Beyer C, Ebli M, Eickenscheidt T, Fiedler S, Förster C, Gensior A, Giebels M, Glatzel S, Heinichen J, Hoffmann M, Höper H, Jurasinski G, Laggner A, Leiber-Sauheitl K et al (2020) A new methodology for organic soils in national greenhouse gas inventories: data synthesis, derivation and application. Ecol Indic 109:1058

Tiemeyer B, Freibauer A, Borraz EA, Augustin J, Bechtold M, Beetz S, Beyer C, Ebli M, Eickenscheidt T, Fiedler S (2020) A new methodology for organic soils in national greenhouse gas inventories: data synthesis, derivation and application. Ecol Ind 109:105838

Tumushabe GW, Muhumuza T, Natamba E, Bird NM, Welham B, Jones L (2013) Uganda national climate change finance analysis. Overseas Development Institute

Turyahabwe N, Banana AY (2008) An overview of history and development of forest policy and legislation in Uganda. Int for Rev 10:641-656

UBA (2017) Germany National Inventory. https:/www.umweltbundesamt.de/en/publikationen/nationalinventory-report-for-german-greenhouse-gas-1. Accessed on 24 Jan 2021

Voigt C, Ferreira F (2016) Differentiation in the Paris agreement. Climate Law 6:58-74

Wang X, Wiser G (2003) The implementation and compliance regimes under the Climate Change Convention and its Kyoto Protocol. Glob Envtl L Ann 135

Weidner H, Mez L (2008) German climate change policy: a success story with some flaws. J Environ Dev 17:356-378

Weiss P, Schieler K, Schadaue K, Englisch M (2000) Die Kohlenstoffbilanz des österreichischen Waldes und Betrachtungen zum Kyoto-Protokoll. Umweltbundesamt Wien

Wellbrock N, Bolte A (2019) Status and dynamics of forests in Germany: results of the national forest monitoring. Springer Nature

Wellbrock N, Grüneberg E, Riedel T, Polley H (2017) Carbon stocks in tree biomass and soils of German forests. Cent EurFor J 63:105-112

Zito AR (2000) Transboundary air pollution. In: Creating environmental policy in the european union. Palgrave Macmillan, London, pp 49-87

Publisher's note Springer Nature remains neutral with regard to jurisdictional claims in published maps and institutional affiliations. 


\section{Authors and Affiliations}

Michael Mugarura ${ }^{1,2}(D)$ Wolfgang Stümer ${ }^{1} \cdot$ Karsten Dunger $^{1} \cdot$ Andreas Bolte $^{1}$. Matt Ramlow ${ }^{3} \cdot$ Emmanuel Ackom $^{4}$. Steffi Röhling ${ }^{1}$

1 Thünen Institute of Forest Ecosystems, Alfred-Moller-Strasse 1, 16225 Eberswalde, Germany

2 Hochschule für nachhaltige Entwicklung Eberswalde (HNEE), Schicklerstraße 5, 16225 Eberswalde, Germany

3 Coalition for Rainforest Nations, 52 Vanderbilt Avenue, 14th Floor, New York, NY 10017, USA

4 Department Technology, Management and Economics - UN City, Denmark Technical University (DTU), Marmorvej 51, 2100 Copenhagen Ø, Denmark 